\title{
The impact of including a medication review in an integrated care pathway: a pilot study
}

\author{
Anaïs Payen ${ }^{1}$, Claire Godard-Sebillotte ${ }^{2}$, Nadia Sourial ${ }^{2}$, Julien Soula ${ }^{1}$, David Verloop ${ }^{3}$, \\ Marguerite-Marie Defebvre ${ }^{3}$, Corinne Dupont ${ }^{3}$, Delphine Dambre ${ }^{2}$, Antoine Lamer ${ }^{1}$, and \\ Jean-Baptiste Beuscart ${ }^{1}$ \\ ${ }^{1}$ Univ. Lille, CHU Lille, ULR 2694 - METRICS : Évaluation des technologies de sante et \\ des pratiques médicales, F-59000 Lille, France, \\ ${ }^{2}$ Affiliation not available \\ ${ }^{3}$ Agence Régionale de Sante Hauts-de-France, Lille, France
}

December 20, 2021

\begin{abstract}
Objective: Our hypothesis was that the intervention would decrease (or at least not increase) the number of potentially inappropriate medications (PIMs) and the number of hospital readmissions within 30 days of discharge per hospital stay. Methods: A cohort of hospitalized older adults enrolled in the PAERPA integrated care pathway (the exposed cohort) was matched retrospectively with hospitalized older adults not enrolled in the pathway (unexposed cohort) between January 1st, 2015, and December 31st, 2018. It was an analysis of French health administrative database. The inclusion criteria for exposed patients were admission to an acute care department in general hospital, age 75 or over, at least three comorbidities or the prescription of diuretics or oral anticoagulants, discharge alive, and performance of a medication review. Results: For the study population $(\mathrm{n}=582)$, the mean \pm standard deviation age was $82.9 \pm 4.9$, and $190(65.3 \%)$ were women. Depending on the definition used, the overall median number of PIMs ranged from 2 [0;3] upon admission to 3 [0;3] at discharge. The intervention was not associated with a significant difference in the mean number of PIMs. Patients in the exposed cohort were half as likely to be readmitted to hospital within 30 days of discharge, relative to patients in the unexposed cohort. Conclusion: Our results show that a medication review was not associated with a decrease in the mean number of PIMs. However, the integrated care intervention including the medication review was associated with a reduction in the number of hospital readmissions at 30 days.
\end{abstract}

\section{Hosted file}

Article_PIMS-fv.docx available at https://authorea.com/users/451987/articles/550168-theimpact-of-including-a-medication-review-in-an-integrated-care-pathway-a-pilot-study 


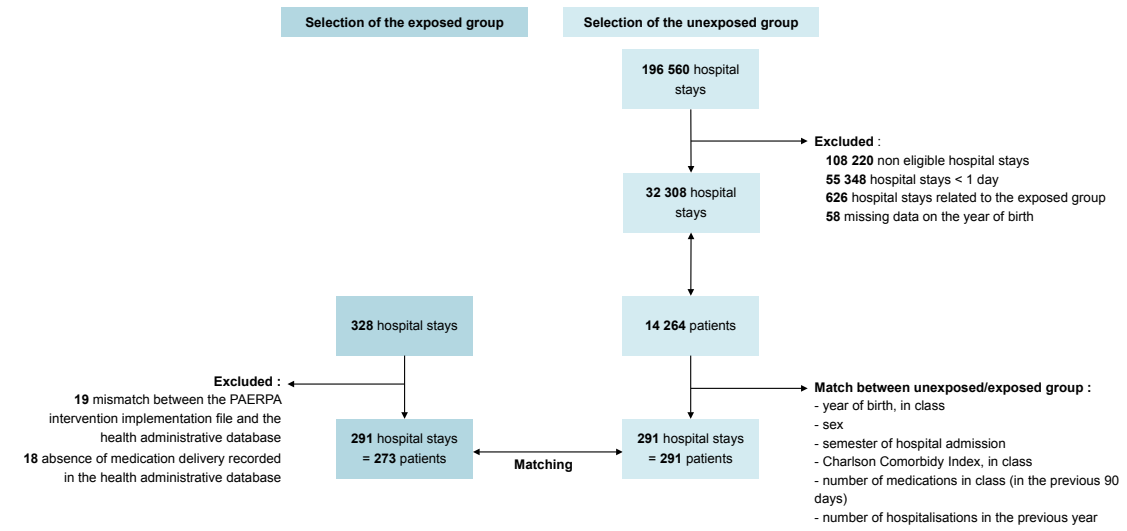




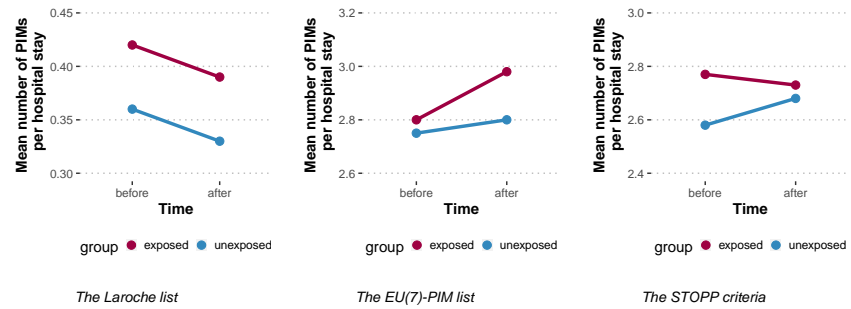

Figure 1 The number of PIMs (according to the Laroche list, the EU(7)-PIM list and the STOPP criteria) in the 90 days before admission vs. the 90 days after discharge for the exposed and unexposed cohorts. 


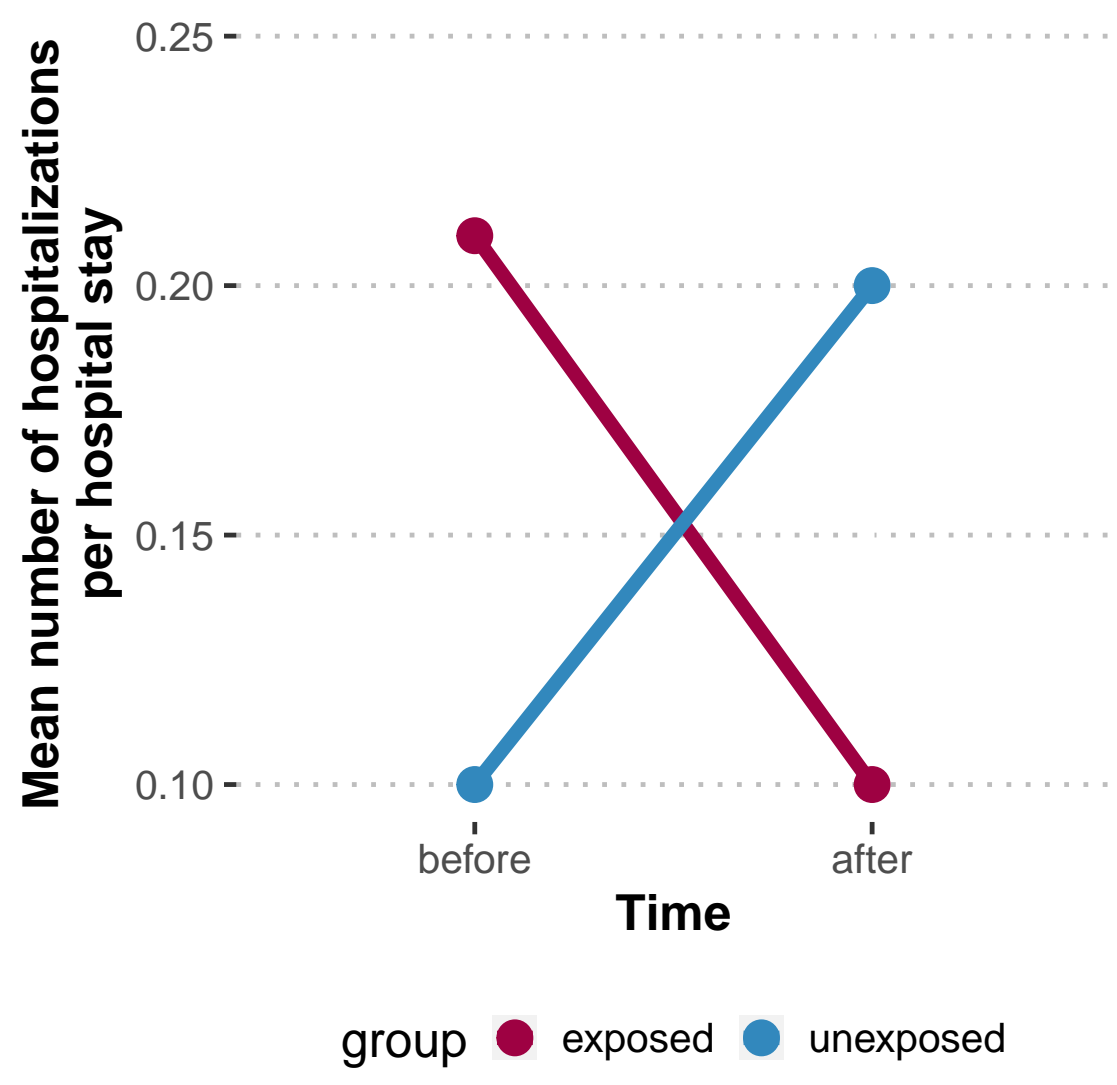

Hosted file

Table_PIMS_1.xlsx available at https://authorea.com/users/451987/articles/550168-the-impactof-including-a-medication-review-in-an-integrated-care-pathway-a-pilot-study

Hosted file

Table_PIMS_2.xlsx available at https://authorea.com/users/451987/articles/550168-the-impactof-including-a-medication-review-in-an-integrated-care-pathway-a-pilot-study 